\title{
HETEROKARYON COMPATIBILITY IN THE ASPERGILLUS GLAUCUS LINK GROUP
}

\author{
DAVID A. JONES \\ Department of Genetics, The University, Birmingham
}

Received g.ix. $6_{4}$

\section{INTRODUCTION}

THERE are two main functions of sexual reproduction; the reassortment of genetic variability and the production of younger individuals from those which are ageing. The latter is probably a secondary effect of the process. With homothallic sexually reproducing fungi heterokaryosis is prerequisite for the redistribution of genetic information at meiosis yet Grindle ( $1963 a, b)$ has shown that the frequency of heterokaryon formation between different isolates of Aspergillus nidulans Eidam is very low. He found moreover, that regardless of the locality from which they were derived, the compatible isolates were usually extremely similar in morphology. Jinks (1959) discovered marked ageing effects in the related fungus Aspergillus glaucus, this being exemplified by the reduction in the number of perithecia formed and the onset of vegetative death. Although with Aspergillus nidulans Jinks (1954) obtained a form without perithecia after I 4 propagations by asexual spores and Croft ( 1964$)$ has reduced the perithecial density in some isolates by selective techniques, vegetative death has not yet been observed in this fungus. Because of this difference between the two species the frequency of heterokaryon formation in Aspergillus glaucus is now of particular interest.

This report describes studies on the ability of wild isolates of Aspergillus glaucus to form heterokaryons voluntarily, that is without the use of auxotrophs.

\section{MATERIALS AND METHODS}

Wild isolates of Aspergillus glaucus were obtained from samples of soil or by exposing agar plates to the air in suitable localities. A list of these isolates is given in table 1 . The nomenclatural system of Thom and Raper (1945) has been adopted but "Aspergillus glaucus" will be used as a collective term for the four species described. Only one of morphologically similar isolates obtained from the same locality was retained.

Two complementary conidiospore colour mutants, one orange and the other white, were obtained for each isolate by UV irradiation. By complementary it is implied that when these mutants are found together in an heterokaryotic conidial head the phenotype produced is wild type (green).

Colonies were grown on Plunkett's medium (1953) to which had been added 4 per cent. $\mathrm{NaCl}$. The increase in conidiospore production noted by Grindle ( $1963 a)$ for Aspergillus nidulans can also be demonstrated for Aspergillus glaucus. The $p \mathrm{H}$ of the medium was adjusted to approximately $5 \cdot 8$. 
The formal tests for heterokaryon compatibility were conducted as follows. Hyphal inocula of orange and white conidiospore mutants were placed side by side $1 \mathrm{~mm}$. apart on agar plates. On each plate two within isolate crosses (selfs) and the reciprocal crosses between the two isolates were set up. After ro days incubation

TABLE I

List of wild isolates

\begin{tabular}{|c|c|c|c|c|}
\hline $\begin{array}{l}\text { Isolate } \\
\text { number }\end{array}$ & Species & $\begin{array}{l}\text { Date of } \\
\text { isolation }\end{array}$ & Source & $\begin{array}{l}\text { Method of } \\
\text { isolation }\end{array}$ \\
\hline $\begin{array}{l}2 \\
14 \\
31 \\
32 \\
33 \\
34 \\
35 \\
36 \\
37 \\
38 \\
39 \\
40 \\
41 \\
42 \\
43 \\
44 \\
45 \\
46 \\
49 \\
50 \\
55 \\
56 \\
57 \\
59 \\
110 \\
111 \\
112 \\
113 \\
114 \\
125 \\
126 \\
127 \\
128 \\
129 \\
130\end{array}$ & $\begin{array}{l}\mathrm{ch} \\
\mathrm{ch} \\
\mathrm{am} \\
\mathrm{am} \\
\mathrm{re} \\
\mathrm{am} \\
\mathrm{am} \\
\mathrm{am} \\
\mathrm{am} \\
\mathrm{am} \\
\mathrm{am} \\
\mathrm{am} \\
\mathrm{am} \\
\mathrm{re} \\
\mathrm{re} \\
\mathrm{re} \\
\mathrm{re} \\
\mathrm{ch} \\
\mathrm{am} \\
\mathrm{am} \\
\mathrm{ch} \\
\mathrm{am} \\
\mathrm{am} \\
\mathrm{am} \\
\mathrm{am} \\
\mathrm{am} \\
\mathrm{am} \\
\mathrm{ch} \\
\mathrm{am} \\
\mathrm{am} \\
\mathrm{ch} \\
\mathrm{um} \\
\mathrm{am} \\
\mathrm{am} \\
\mathrm{ch}\end{array}$ & $\begin{array}{l}? \\
1961 \\
1962 \\
1962 \\
1962 \\
1962 \\
1962 \\
1962 \\
1962 \\
1962 \\
1962 \\
1962 \\
1962 \\
1962 \\
1962 \\
1962 \\
1962 \\
1962 \\
1962 \\
1962 \\
1962 \\
1962 \\
1962 \\
1962 \\
1962 \\
1962 \\
1962 \\
1962 \\
1962 \\
1962 \\
1963 \\
1963 \\
1963 \\
1963 \\
1963\end{array}$ & $\begin{array}{l}\text { Edgbaston } \\
\text { Kings Norton } \\
\text { Kings Norton } \\
\text { Kings Norton } \\
\text { Kings Norton } \\
\text { Kings Norton } \\
\text { Kings Norton } \\
\text { Kings Norton } \\
\text { Kings Norton } \\
\text { Lichfield } \\
\text { Lichfield } \\
\text { Lichfield } \\
\text { Lichfield } \\
\text { Ipswich } \\
\text { Ipswich } \\
\text { Ipswich } \\
\text { Ipswich } \\
\text { Edgbaston } \\
\text { Edgbaston } \\
\text { Edgbaston } \\
\text { Dudley } \\
\text { Dudley } \\
\text { Dudley } \\
\text { Dudley } \\
\text { Frilford Heath (Berks.) } \\
\text { Abergavenny } \\
\text { Abergavenny } \\
\text { Abergavenny } \\
\text { Abergavenny (Warks.) } \\
\text { Yarningfield (Wacking (Somerset) } \\
\text { Locing } \\
\text { Locking } \\
\text { Locking } \\
\text { Locking } \\
\text { Locking }\end{array}$ & $\begin{array}{c}\text { (obtained by Sharpe) } \\
\text { open plate } \\
\text { open plate } \\
\text { open plate } \\
\text { open plate } \\
\text { open plate } \\
\text { open plate } \\
\text { open plate } \\
\text { open plate } \\
\text { open plate } \\
\text { open plate } \\
\text { open plate } \\
\text { open plate } \\
\text { open plate } \\
\text { open plate } \\
\text { open plate } \\
\text { open plate } \\
\text { open plate } \\
\text { open plate } \\
\text { open plate } \\
\text { soil } \\
\text { soil } \\
\text { soil } \\
\text { soil } \\
\text { soil } \\
\text { soil } \\
\text { soil } \\
\text { soil } \\
\text { soil } \\
\text { soil } \\
\text { soil } \\
\text { soil } \\
\text { soil } \\
\text { soil } \\
\text { soil }\end{array}$ \\
\hline
\end{tabular}

am, A. amstelodami; ch, A. chevalieri; re, A. repens and um, A. umbrosus.

in the dark at $25^{\circ} \mathrm{C}$. the plates were scored for heterokaryons. The number of green heads found at the interface between two colonies was counted, if this was less than 20, and samples of green spores were tested for nuclear segregation. This was done to check that the wild type colour of the asexual spores was the result of heterokaryosis and not syntropy.

\section{RESULTS}

The principle conclusion to be drawn from the results presented in table 2 is that if an isolate readily forms heterokaryons with itself it is more likely to form an heterokaryon with another isolate, particularly with a good selfer. There are three categories of cross. Some isolates 
TABLE 2

Tests of heterokaryon compatibility within populations

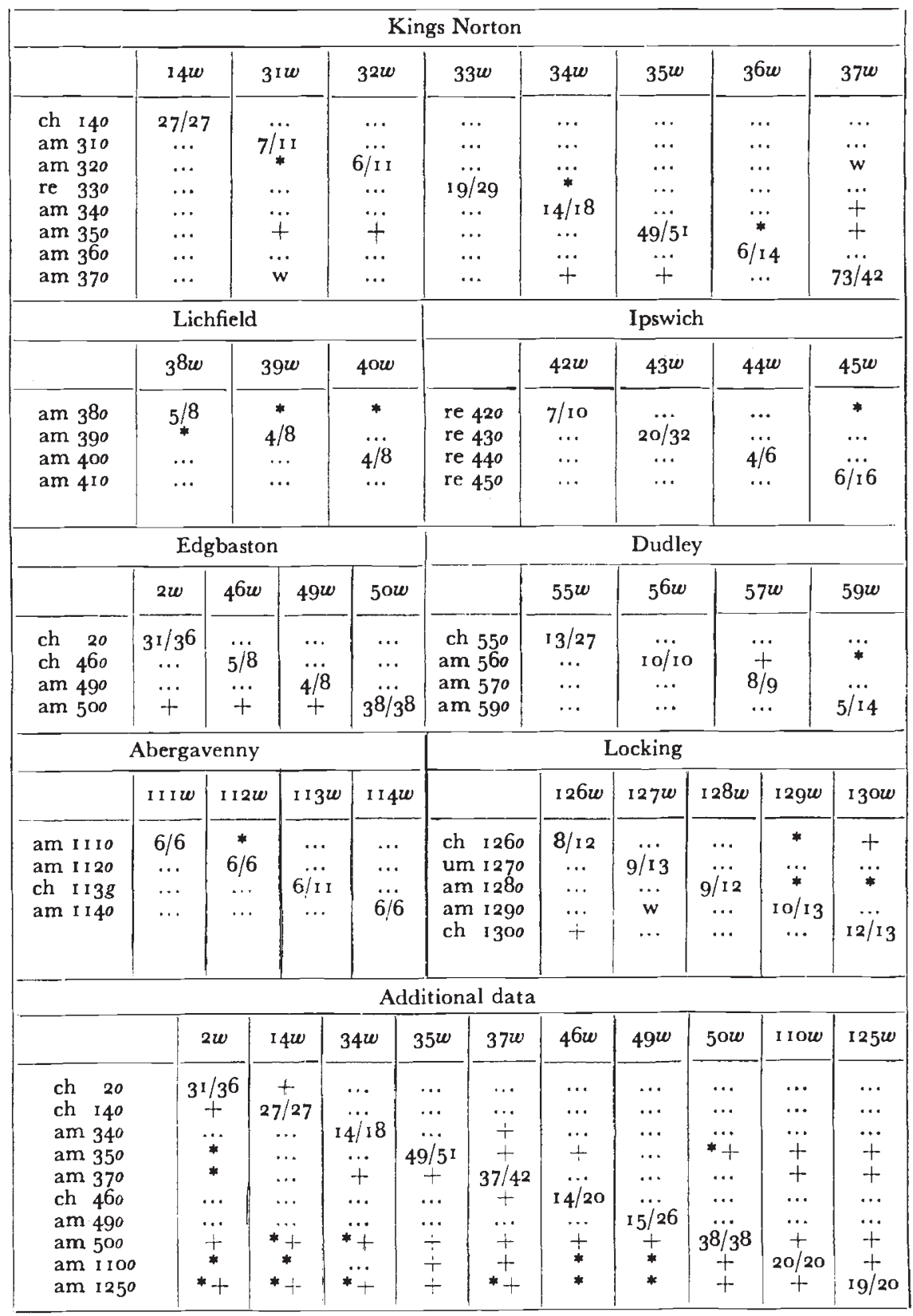

The entries under selfs indicate the number of replicates in which heterokaryotic heads were produced.

At least six replicates of each cross were made but the failure of selfs was not recorded for the early tests. The readiness with which two isolates cross has not been scored quantitatively as no adequate methods for doing so have yet been devised. I I o and I 25 were the only isolates obtained from Frilford Heath and Yarningfield respectively.

Key: + green heads shown to be heterokaryotic, * green heads homokaryotic, w weak green pigmentation of a white head giving 2 per cent. orange colonies on testing, ... no green or mixed heads observed. No orange mutant was obtained for I I 3 and no white mutant was induced in $4 \mathrm{I}$. 
can cross reciprocally; that is the white mutant of one isolate forms heterokaryons with the orange mutant of the other and vice versa. Some isolates can cross one way but not reciprocally (non-reciprocal heterokaryosis). Finally, the majority of isolates do not form heterokaryons with any of the others against which they have been tested.

In the first category are the crosses $2 \times 14,34 \times 37,126 \times 130$ and the group $35,37,5^{\circ}$, I 10 and 125 (excluding $37 \times 5^{\circ}$ ). Even though 34 crosses only with 37 there could still be gene flow (this has not been demonstrated) from 34 to the other members of the large group via 37. It is therefore reasonable to consider that $34,35,37,5^{\circ}, I_{10}$ and 125 belong to the same compatibility group. It is apparent also that isolates 2 and 1 4, 126 and 130 constitute independent groups.

Amongst the second category are the crosses $37 \times 46,35 \times 46$, $2 \times 125$ and $14 \times 125$. The last two are being investigated further as they represent heterokaryon formation between Aspergillus chevalieri and Aspergillus amstelodami. The avidity with which 50 orange forms heterokaryons is discussed below.

\section{DISCUSSION}

\section{(i) The volidity of the tests}

Carr and Olive (1959) have shown that the observation of hyphal anastamosis does not in itself give proof of heterokaryon compatibility. The only unambiguous test is to extract from one hyphal tip or conidiospore both the nuclei that went into it. This is the original method used by Beadle and Coonradt (1944) for Neurospora and at present it cannot be bettered.

The conidiospores of Aspergillus glaucus usually contain at least two nuclei (see table 3 ) and thus a conidiospore may be homokaryotic or

TABLE 3

The number of nuclei in the conidiospores of Aspergillus glaucus

\begin{tabular}{|c|c|c|c|c|c|}
\hline $\begin{array}{c}\text { Number of nuclei } \\
\text { Frequency (per cent.) }\end{array}$ & $22 \cdot 9$ & $65 \cdot 2$ & $10 \cdot 1$ & $1 \cdot 8$ & 676 \\
\hline
\end{tabular}

Data of J. L. Jinks, collected by direct observation of young conidia.

heterokaryotic. A green conidial head produced at the interface between two spore-colour-mutant colonies may be the result of heterokaryosis or of syntropy. If a green head is the result of heterokaryosis then, on single spore transfer, at least two types of colony will be obtained. On the other hand, a green head caused by syntropy will produce only one type of colony. Hence it is necessary to test samples of green heads in order to distinguish between the two types.

Some isolates were known to produce conidial heads with spores of two colours, e.g. columns of mutant and columns of green spores in the same head. These were noted when the mutants were originally 
obtained. On selfing white by orange any conidial head containing both white and orange spores give unambiguous proof of heterokaryosis (Grindle, 1963a). The crosses involving the isolates apparently containing uninucleate conidiospores were examined very carefully for mixed asexual heads.

When one isolate does not self there is no criterion for judging the significance of the lack of inter-isolate heterokaryon compatibility. All the strains used in these experiments will self but the frequency of heterokaryotic heads depends on the conditions of growth (Jones, unpublished). This in itself is a manifestation of the variability within the group. The test depends upon the ability of heterokaryotic mycelia to give rise to heterokaryotic conidial heads which can be recognised as such. Thus intra-conidial complementation is an obligatory requirement for the detection of heterokaryosis in a binucleate conidiospore.

\section{(ii) Significance of the results}

Analysis of variance of the growth rates and morphology of the Aspergillus amstelodami and Aspergillus chevalieri isolates is given in table 4 . For Aspergillus amstelodami the variance ratios for growth rate on Plunkett's medium and for the production of conidial heads in concentric rings are bordering on significance. For the seven Aspergillus chevalieri isolates only the variance ratio for growth rate on Plunkett's medium is significant.

Thus with the limited data to hand no predictions can be made as to whether two isolates of Aspergillus amstelodami will form heterokaryons merely by comparing their morphology. There is the possibility that growth rate of Aspergillus chevalieri on Plunkett's medium may be a useful character but it can be shown that the large variance ratio is due entirely to the $2 / 14$ group. Grindle ( ${ }^{96} 6_{3} b$ ) was able to show that highly compatible isolates of Aspergillus nidulans are identical or extremely similar in surface morphology. This is not true for the Aspergillus glaucus group.

A comparison between the frequencies of heterokaryon formation in Aspergillus nidulans and Aspergillus glaucus is relevant here. Table 5 gives this information. However the data are arranged the frequency of heterokaryon formation in Aspergillus glaucus is considerably lower than in Aspergillus nidulans.

The orange mutant of isolate $5^{0}$ (and to a lesser extent the orange mutants of isolates $3^{2}$ and $5^{6}$ (data not given)) forms heterokaryons with the white mutant of every isolate against which it has been tested. If only isolate 500 behaved in this way it could be possible that 500 is both a spore colour and a compatibility mutant. It is unlikely that three spore colour-incompatibility mutants should have occurred amongst the 35 orange mutants so far studied unless the loci concerned are very close together. There is no further evidence on this point but it can be stated that the ease of complementation is irrelevant, 
for most of the green heads which have been tested, with 500 as one parent, were heterokaryotic. Isolate 50 produces a dense mass of conidial heads and thus it is possible that there is a greater chance for

\section{TABLE 4}

Analysis of variance of some growth characteristics of the isolates listed in table I. The two species A. amstelodami and A. chevalieri are considered. For A. amstelodami the group 34, 35, 37, IIO and 125 is compared with the remainder while for A. chevalieri the breakdown is 2,$14 ; 126,130 ; 46,55,113$

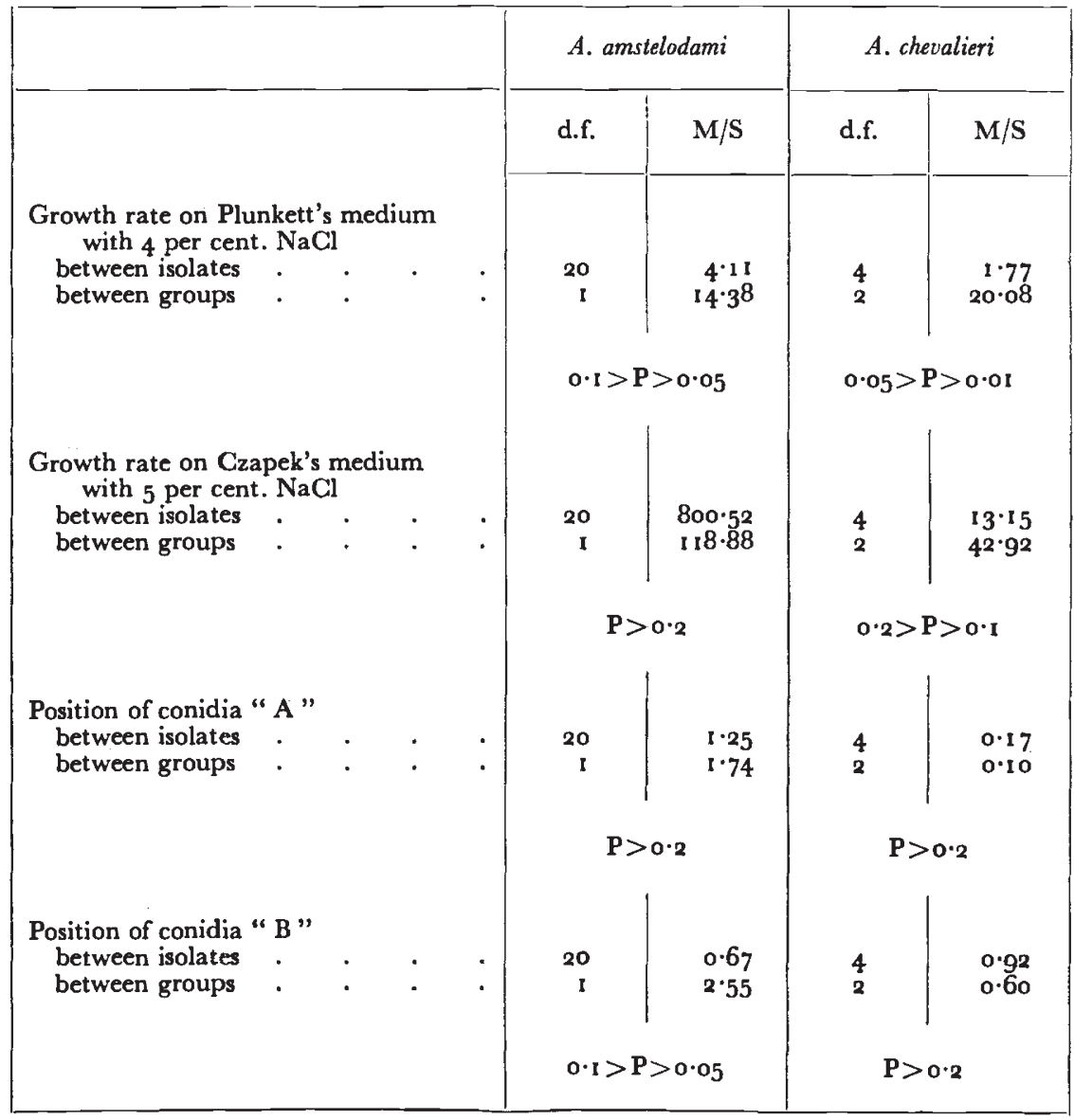

The position of the conidia relative to the perithecia at the edge of a colony is characteristic for each isolate. In "A" the colonies have been scored I for conidial heads produced before perithecia, 2 for conidial heads and perithecia produced simultaneously and 3 for perithecia produced before conidial heads.

Some colonies produce conidial heads in concentric rings when grown in normal daylight conditions. In " $B$ " the colonies have been scored $\mathrm{I}$ for conidial heads produced in concentric rings, 2 conidial heads occasionally produced in concentric rings and 3 isolates regularly producing conidial heads not in concentric rings.

any heterokaryon formed to produce heterokaryotic heads. This does, however, also assume a second difference between the white and orange nuclei of isolate 50 - the readiness with which a green head is produced. 
Why an isolate can form non-reciprocal heterokaryons is not known. If both selfs and one cross give green heads it is unlikely that the lack of production of green heads by the reciprocal cross is due to noncomplementation for, presumably, the mutations to white and orange conidiospores involve different major units of function of structural genes. Additional spore colour mutants are being induced in these isolates to analyse this phenomenon further.

TABLE 5

The frequencies of heterokaryon formation in Aspergillus nidulans and Aspergillus glaucus

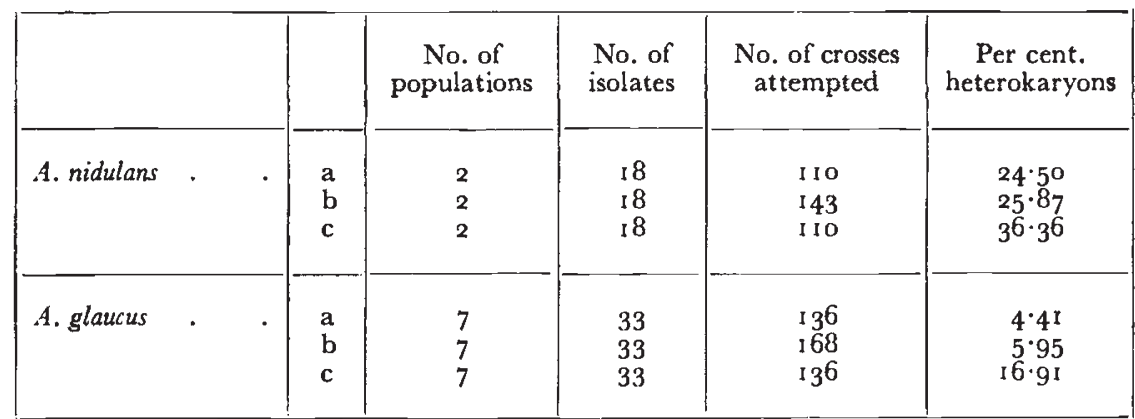

Data for Aspergillus nidulans from Grindle (1963b). Isolates 110 and 125 of Aspergillus glaucus are omitted. Key: (a) within population crosses only; (b) total data; (c) within population crosses only but including weak and non-reciprocal crosses in the " heterokaryon" class.

\section{(iii) Quantitative estimates of heterokaryosis}

In some of the crosses, e.g. $14 w \times 125^{\circ}$ and $50 w \times 35^{\circ}$, both syntropy and heterokaryosis have been detected. The frequency of green heads at an interface cannot therefore give a quantitative estimate of heterokaryon compatibility unless every green head produced is tested. It is often not possible to sample a green head without, by chance, picking up some adjacent orange or white spores and thus syntropic green heads could easily be classified as heterokaryotic. Sampling all the green heads would probably not add precision to the work unless a method could be devised for picking up individual spores of known phenotype.

\section{(iv) Consequences of the results}

Aspergillus glaucus is homothallic, producing ascospores without the need for a previous fusion of hyphæ of opposite mating type. There is therefore no obligatory outbreeding mechanism and any hyphal fusion which does occur will be voluntary. In homothallic species meiosis will lead to no increase in variation in a homokaryon and yet meiosis does give rise to recombination between linked mutants in Aspergillus glaucus (Jinks, Sharpe, unpublished). The results described above indicate that heterokaryon formation is not a common phenomenon but, in spite of this, sexual reproduction is retained. There appear to be two possible reasons for this. Heterokaryosis, although rare, may occur frequently enough for the sexual process to be advantageous. 
Secondly, it has been shown that the ætiology of vegetative death is cytoplasmic (Jinks, 1959) and that the ageing of a clone is not due to the differentiation of the nuclei. Hence in order to survive, this fungus must necessarily pass through the sexual stage, a process by which the ageing cytoplasm is restandardised and younger individuals are produced.

Aspergillus glaucus is a highly sexual fungus and yet the frequency with which heterokaryons are formed is both small and unpredictable. There seems to be a physiological separation of sympatric types, the reverse of the incompatibility systems in some higher plants, which limits the gene flow between them. Thus in addition to Aspergillus nidulans (Grindle, $1963 a, b$ ) Aspergillus glaucus reveals a mechanism acting against the free flow of variation from population to population.

Acknowledgments.-I am most grateful to Dr J. L. Jinks for his advice and encouragement and to Professor K. Mather, F.R.s., for his help with presentation of this report.

\section{SUMMARY}

Thirty-five different wild isolates of Aspergillus glaucus obtained from nine localities have been tested for their ability to form heterokaryons with each other. The test used relied on the production of heterokaryotic green or mixed conidial heads after the hyphal anastamosis of orange and white conidiospore producing colonies. The results show:

I. An isolate whose mutants readily form heterokaryons with each other is more likely to form an heterokaryon with another isolate, particularly with another good selfer.

2. The majority of isolates obtained from the same locality did not form heterokaryons with each other.

3. There were no basic similarities nor differences between the isolates which did form heterokaryons.

4. Many of the strains studied appear to be genetically isolated from each other.

\section{REFERENCES}

BEAdLE, G. W., AND COONRADT, v. L. 1944. Heterokaryosis in Neurospora crassa. Genetics, 29, 291-308.

CARR, A. J. H., AND OLIVE, L. s. 1959. Genetics of Sordaria fimicola. III. Cross compatibility among self-fertile and self-sterile cultures. Amer. F. Bot., 46, 81-91. CROFT, J. H. 1964. Ph.D. Thesis, University of Birmingham.

GRINDLE, M. 1963a. Heterokaryon compatibility of unrelated strains in the Aspergillus nidulans group. Heredity, 18 , 19 1-204.

GRINDLE, M. 1963b. Heterokaryon compatibility of closely related wild isolates of Aspergillus nidulans. Heredity, ${ }^{2} 8,397-405$.

JINKS, J. L. I954. Somatic selection in fungi. Nature, $174,409-410$.

JINKs, J. L. 1959. Lethal suppressive cytoplasms in aged clones of Aspergillus glaucus. F. gen. Microbiol., 21, 397-409.

PLUNKETT, B. E. 1953. Nutritional and other aspects of fruit body production in pure cultures of Collybia velutipes (Curt.). Fr. Ann. Bot. NS., I7, 193-21 7 .

THOM, C., AND RAPER, к. B. 1945. A Manual of the Aspergilli. Williams \& Wilkins Co., Baltimore, U.S.A. 